\title{
Acute kidney injury and other factors associated with mortality in hiv-infected patients
}

\author{
Geraldo Bezerra da Silva Junior ${ }^{1}$ \\ Sérgio Luiz Arruda Parente Filho ${ }^{2}$ \\ Douglas de Sousa Soares ${ }^{2}$ \\ Rodrigo da Nóbrega de Alencar ${ }^{2}$ \\ Tiago Tomaz Teles Peixoto ${ }^{2}$ \\ Isadora Sales Nogueira ${ }^{2}$ \\ Antônio Mendes Ponte de Oliveira Filho ${ }^{2}$ \\ Fernanda Holanda Menezes ${ }^{2}$ \\ Malena Gadelha Cavalcante ${ }^{3}$ \\ Roberto da Justa Pires Neto ${ }^{4}$ \\ Elizabeth de Francesco Daher ${ }^{2,3}$
}

1. School of Medicine, Public Health and Medical Sciences Post-Graduation Programs, Health Sciences Center, University of Fortaleza. Fortaleza, Ceará, Brasil. 2. Department of Internal Medicine, School of Medicine, Federal University of Ceará Fortaleza, Ceará, Brasil. 3. School of Medicine, Medical Sciences and PharmacologyPost-Graduation Programs, Federal University of Ceará. Fortaleza, Ceará, Brasil. 4. Department of Community Health, Public Health Post-Graduation Program, School of Medicine, Federal University of Ceará. Fortaleza, Ceará, Brasil.

\section{SUMMARY}

OBJECTIVE: HIV-related mortality is still high, especially in developed countries. The aim of this study is to investigate factors associated to death in HIV-infected patients.

METHODS: This is a cross-sectional study with all HIV adult patients admitted to a tertiary infectious diseases hospital in Fortaleza, Northeast Brazil, from January 2013 to December 2014. Patients were divided into two groups: survivors and non-survivors. Demographical, clinical and laboratory data were compared and a logistic regression was performed in order to investigate risk factors for death. $P$ values $\leq 0.05$ were considered statistically significant.

RESULTS: A total of 200 patients with mean age of 39 years were including in the study, $69.5 \%$ males. Fifteen patients (7.5\%) died. Non-survivors presented a higher percentage of males (93.3 vs. 67.3\%, $p=0.037)$. Non-survivors presented AKI (73.3 vs. 10.3\%, $p<0.001)$, liver dysfunction (33.3 vs. 11.5, $p=0.031$ ), dyspnea (73.3 vs. 33.0\%, $p=0.002$ ) and disorientation (33.3 vs. 12.4\%, $p=0.025)$ more frequently. Non- survivors also had higher levels of urea (73.8 $\pm 52.7 \mathrm{vs} .36 .1 \pm 29.1 \mathrm{mg} / \mathrm{dL}, p<0.001)$, creatinine $(1.98 \pm 1.65 \mathrm{vs} .1 .05 \pm 1.07 \mathrm{mg} / \mathrm{dL}, p$ < 0.001), aspartate aminotransferase (130.8 vs. $84.8 \mathrm{U} / \mathrm{L}, p=0.03$ ), alanine aminotransferase (115.6 vs. $85.4 \mathrm{U} / \mathrm{L}, p=0.045)$ and lactate dehydrogenase (LDH) (1208 vs. $608 \mathrm{U} / \mathrm{L}, p=0.012)$, as well as lower levels of bicarbonate (18.0 $\pm 4.7 \mathrm{vs} .21 .6 \pm 4.6 \mathrm{mEq} / \mathrm{L}, p=0.016)$ and PCO2 (27.8 \pm 7.7 vs. $33.0 \pm 9.3 \mathrm{mmHg}, p=0.05)$. In multivariate analysis, disorientation $(p=0.035, \mathrm{OR}=5.523,95 \% \mathrm{Cl}=1.130-26.998)$, dyspnoea $(p=0.046, O R=4.064,95 \% \mathrm{Cl}=1.028-16.073), \mathrm{AKI}(p<0.001, \mathrm{OR}=18.045,95 \% \mathrm{Cl}=4.308-75.596)$ and disseminated histoplasmosis $(p=0.016, O R=12.696,95 \% \mathrm{Cl}=1.618-99.646)$ and $\mathrm{LDH}>1000 \mathrm{U} / \mathrm{L}(p=0.038, \mathrm{OR}=4.854,95 \% \mathrm{Cl}=1.093-21.739)$ were risk factors for death. ]CONCLUSION: AKI and disseminated histoplasmosis $(D H)$ were the main risk factors for death in the studied population. Neurologic and respiratory impairment as well as higher levels of LDH also increased mortality in HIV-infected patients.

KEYWORDS: HIV. Mortality. Risk factors. Histoplasmosis. Lactate dehydrogenase.

DATE OF SUBMISSION: 26-Sep-2017

DATE OF ACCEPTANCE: 02-Nov-2017

CORRESPONDING AUTHOR: Geraldo Bezerra da Silva Junior

Av Washington Soares, 1321, Bloco S, Sala 1

Fortaleza - Ceara - Brasil - 60811-905

E-mail: geraldobezerrajr@yahoo.com.br

sergioparente_@hotmail.com, douglas.sousa.soares@gmail.com, rodrigoalencar@gmail.com, tiagotomaz@yahoo.com.br, isadorasales@gmail.com, antoniomendes@gmail.com, fernandamenezes@hotmail.com, malenagadelha@hotmail.com robertojusta@gmail.com,ef.daher@uol.com.br 


\section{INTRODUCTION}

According to the United Nations Program on HIV/ AIDS (UNAIDS)', an estimated 36.7 million people worldwide were living with HIV in 2015, while 2.1 million people were infected in the same year. This alarming epidemiologic situation confirms the role of HIV infection as an undoubtedly severe public health issue, which leads to an estimated annual spending of 19 billion dollars and over a million deaths every year' ${ }^{1}$.

In the late 90s, the association of multiple antiretroviral drugs was a milestone in the management of HIV infection, initiating the highly active antiretroviral therapy (HAART) era. The access to HAART has increased since then, reaching more than 17 million people in $2015^{2}$. Several studies have demonstrated the efficacy of such treatment in reducing viral RNA copies, preserving CD4 cells, and consequently decreasing morbidity and mortality ${ }^{3}$. On the other hand, HAART has been associated with significant adverse effects, such as liver dysfunction, skin rash, hypertension, diabetes, dyslipidemia, myocardial infarction and nephrotoxicity ${ }^{4,5}$.

After the extensive introduction of HAART in developed countries of Western Europe and the United States in 1996, HIV-associated mortality has markedly decreased. In these countries, the leading causes of HIV-related death have been changing significantly, shifting from opportunistic infectious diseases to chronic conditions ${ }^{6}$. On the other hand, the national provision of HAART in Latin America started from 1997 to 2004 and Brazil was the first country in the region to establish policies to provide free and universal access to these medications. A study showed that only six out of eleven studied countries in the area presented a decline in HIV mortality from 1997 to 2007 , probably due to this delay in implementing such free-access policies ${ }^{7}$.

Considering the importance of the theme, the aim of this study is to investigate factors associated with death in HIV-infected patients.

\section{METHODS}

\section{Study Design}

This is a cross-sectional study with 200 HIV infected patients admitted to the São José Infectious Diseases Hospital, in Fortaleza, Northeast of Brazil, from January 2013 to December 2014. This hospital is a reference for all infectious diseases in the state of Ceará, in Northeast Brazil. All patients included were $\geq 16$ years old, with a confirmed diagnosis of HIV infection. According to the protocol of the Brazilian Ministry of Health, at least two different tests must be used to confirm HIV infection, including enzyme-linked immunosorbent assay (ELISA), simple/rapid test devices, and western blot. All patients with previous estimated glomerular filtration rate (eGFR) $<60 \mathrm{ml} / \mathrm{min} / 1.73 \mathrm{~m}^{2}$, heart failure, nephrolithiasis, use of nephrotoxic drugs (except for antiretrovirals), or other conditions that may affect renal function were excluded. Patients were divided into two different groups for comparison: those who died after admission (non-survivors) and those who did not (survivors).

\section{Treatment}

For those patients who were in HAART previously to admission, treatment included: zidovudine (AZT), didanosine (ddI), lamivudine (3TC), stavudine (D4T), abacavir (ABC), tenofovir disoproxil fumarate (TDF), lopinavir (LPV), saquinavir (SQV), ritonavir (RTV), amprenavir (APV), efavirenz (EFZ), and nevirapine (NPV), according to the protocols of the Brazilian Ministry of Health.

\section{Definitions}

Acute kidney injury (AKI) was defined and classified according to the Kidney Diseases Improving Global Outcomes (KDIGO) criteria ${ }^{8}$. Hypotension was defined as mean arterial blood pressure (MAP) $<60 \mathrm{mmHg}$, and therapy with vasopressors was initiated when the MAP remained $<60 \mathrm{mmHg}$, despite adequate fluid administration. Oliguria was defined as urine output $<0.5 \mathrm{ml} / \mathrm{kg} / \mathrm{h}$ after adequate fluid replacement. Hemodialysis was indicated for those patients that remained oliguric after effective hydration, in cases with uremia-associated hemorrhagic phenomena or severe respiratory failure, as well as for patients with treatment-refractory hyperkalemia and metabolic acidosis.

Thrombocytopenia was defined as platelets count lower than $150,000 / \mathrm{mm}^{3}$ and anemia as hemoglobin (Hb) $<12 \mathrm{~g} / \mathrm{dL}$. The occurrence of metabolic acidosis was evidenced when $\mathrm{pH}<7.35$ and serum bicarbonate $<20 \mathrm{mEq} / \mathrm{L}$, and severe metabolic acidosis when $\mathrm{pH}<7$.10. Liver dysfunction was defined as the elevation of aspartate aminotransferase (AST) or alanine aminotransferase (ALT) >120U/L (three times higher than the normal range). All associated infections were diagnosed by the attendant clinicians during hospitalization and were confirmed by serologic or 
laboratory tests, when possible. Disseminated histoplasmosis (DH), specifically, was diagnosed by identification of $H$. capsulatum in peripheral blood smear, bone marrow aspirate, blood and bone marrow culture, or histopathology of different tissues.

\section{Studied parameters}

Clinical and demographical parameters included age, gender, hospitalization time, main signs and symptoms on admission, the occurrence of associated infections, previous HAART use, AKI development, hemodialysis requirement, and death. All infectious diseases other than HIV presented by the patients, opportunistic or not, were considered "associated infections". Laboratory assessment included: mean HIV viral load, CD4 lymphocytes count, serum urea and creatinine, hemoglobin $(\mathrm{Hb})$, hematocrit, leukocytes count, platelets count, sodium, potassium, aspartate amino transaminase (AST), alanine aminotransaminase (ALT), and lactate dehydrogenase (LDH). Arterial blood gas analysis included arterial $\mathrm{pH}$, carbon dioxide partial pressure $\left(\mathrm{pCO}_{2}\right)$, and bicarbonate $\left(\mathrm{HCO}_{3}\right)$.

\section{Statistics}

Statistical analysis was executed using the SPSS software for Windows version 20.0 (IBM, USA) and its results were expressed through tables. The Kolmogorov-Smirnov test was used for numeric variables in order to assess variable distribution. Variables with normal distribution were expressed through mean \pm standard deviation (SD). Variables with non-normal distribution were expressed through median values. A comparison of categorical variables was executed using Pearson's Chi-square, while numerical variables were compared using Student's T-test (for variables with normal distribution) or Mann-Whitney $\mathrm{U}$ test (for variables with non-normal distribution). $P$ values $\leq 0.05$ were considered statistically significant. In order to evaluate risk factors for death, a logistic regression model was used for categorical variables. All variables with statistical significance in univariate analysis were included in multivariate analysis. Adjusted odds ratios (ORs) and 95\% confidence intervals (CIs) were calculated.

\section{Ethics}

This study was reviewed and approved by the Ethics Committee of São José Infectious Disease Hospital.

\section{RESULTS}

A total of 200 patients were included in the studied, $69.5 \%$ male. The mean age was 39 years, ranging from 16 to 74 years. Fifteen patients (7.5\%) died. The percentage of males was significantly higher in non-survivors than in survivors (93.3 vs. $67.3 \%$, $\mathrm{p}=0.037$ ). Almost half of the patients (49\%) used

TABLE 1 - COMPARISON OF DEMOGRAPHIC DATA, CLINICAL PARAMETERS, COMORBIDITIES, AND OUTCOMES BETWEEN SURVIVORS AND NON-SURVIVORS.

\begin{tabular}{|c|c|c|c|}
\hline & Survivors $(N=185)$ & Non-survivors $(\mathrm{N}=15)$ & p \\
\hline Age (years) & $37.7 \pm 12.1$ & $41.8 \pm 13.9$ & 0.214 \\
\hline \multicolumn{4}{|l|}{ Gender (\%) } \\
\hline Male & $67.6 \%$ & $93.3 \%$ & 0.037 \\
\hline Female & $32.4 \%$ & $6.7 \%$ & \\
\hline Hospitalization time (days) & $18 \pm 15$ & $8 \pm 6$ & 0.005 \\
\hline Previous HAART (\%) & 50.3 & 33.3 & 0.207 \\
\hline \multicolumn{4}{|l|}{ Comorbidities } \\
\hline Diabetes Mellitus (\%) & 3.2 & 13.3 & 0.055 \\
\hline HVB Coinfection (\%) & $0.0 \%$ & $0.0 \%$ & - \\
\hline HVC Coinfection (\%) & $0.0 \%$ & $0.0 \%$ & - \\
\hline \multicolumn{4}{|l|}{ Outcomes } \\
\hline $\mathrm{AKI}(\%)$ & 10.3 & 73.3 & $<0.001$ \\
\hline Hemodialysis (\%) & 2.7 & 46.7 & $<0.001$ \\
\hline
\end{tabular}


HAART previously to the admission, but there was no significant difference between groups (50.3 vs. $33.3 \%, \mathrm{p}=0.207)$. Non-survivors presented a significantly shorter hospital stay ( $8 \pm 6$ vs. $18 \pm 15$ days, $\mathrm{p}=0.005)$, developed more AKI (73.3 vs. 10.3\%, $\mathrm{p}<0.001$ ), had more severe forms of AKI (Stage 3 53.3 vs. $4.5 \%, \mathrm{p}<0.001)$ and needed more hemodialysis (46.7 vs. $2.7 \%, \mathrm{p}<0.001)$ than survivors, as presented in Table 1.

Non-survivors also manifested higher incidence of liver dysfunction (33.3 vs. 11.5, $\mathrm{p}=0.031$ ), dyspnea (73.3 vs. $33.0 \%, p=0.002)$, diarrhea (60.0 vs. $33.0 \%$, $\mathrm{p}=0.035$ ), disorientation (33.3 vs. $12.4 \%, \mathrm{p}=0.025$ ) and oliguria (20.0 vs. $1.6 \%, \mathrm{p}<0.001)$, as summarized in Figure 1. In general, there was no significant difference between groups in associated infection incidence ( 86.7 vs. $68.1 \%, \mathrm{p}=0.133$ ), but non-survivors presented disseminated histoplasmosis (26.7 vs. $3.2 \%, \mathrm{p}<0.001)$ and cryptococcosis (13.3 vs. $2.7 \%$, $\mathrm{p}=0.031$ ) more frequently than survivors, as summarized in Figure 2.

Regarding laboratory evaluation, non-survivors presented lower levels of hematocrit $(28.0 \pm 9.1 \mathrm{vs}$. $32.5 \pm 7.2 \%, p=0.023)$, bicarbonate (18.0 \pm 4.7 vs. 21.6 $\pm 4.6 \mathrm{mEq} / \mathrm{L}, \mathrm{p}=0.016)$ and $\mathrm{PCO} 2(27.8 \pm 7.7 \mathrm{vs} .33 .0 \pm$ $9.3 \mathrm{mmHg}, \mathrm{p}=0.05)$, as well as higher levels of serum urea $(73.8 \pm 52.7 v s .36 .1 \pm 29.1 \mathrm{mg} / \mathrm{dL}, \mathrm{p}<0.001)$, creatinine $(1.98 \pm 1.65$ vs. $1.05 \pm 1.07 \mathrm{mg} / \mathrm{dL}, \mathrm{p}<0.001)$, aspartate aminotransferase (130.8 vs. $84.8 \mathrm{U} / \mathrm{L}$, $\mathrm{p}=0.03$ ), alanine aminotransferase (115.6 vs. 85.4 $\mathrm{U} / \mathrm{L}, \mathrm{p}=0.045)$ and LDH (1208 vs. $608 \mathrm{U} / \mathrm{L}, \mathrm{p}=0.012)$,

FIGURE 1 - Comparison of clinical presentation on admission between survivors and non-survivors.

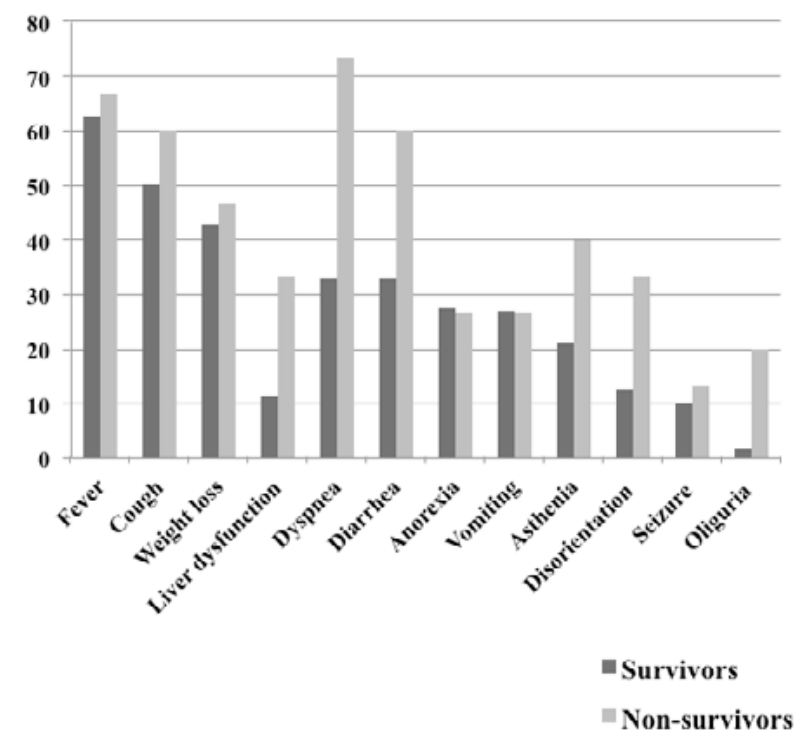

as presented in Table 2 .

In multivariate analysis, disorientation $(\mathrm{p}=0.035$, $\mathrm{OR}=5.523,95 \% \mathrm{CI}=1.130-26.998)$, dyspnea $(\mathrm{p}=0.046$, $\mathrm{OR}=4.064,95 \% \mathrm{CI}=1.028-16.073)$, AKI development $(\mathrm{p}<0.001, \quad$ OR=18.045，95\%CI=4.308-75.596), disseminated histoplasmosis $(\mathrm{p}=0.016, \mathrm{OR}=12.696$, 95\%CI $=1.618-99.646)$ and $\mathrm{LDH}>1000 \mathrm{U} / \mathrm{L}(\mathrm{p}=0.038$, $\mathrm{OR}=4.854,95 \% \mathrm{CI}=1.093-21.739)$ were risk factors for death in HIV infected patients, as evidenced in Table 3.

\section{DISCUSSION}

Despite a remarkable decrease in HIV-related mortality after the introduction of HAART, its rates remain notably high, especially in developing countries. The leading causes of death in these patients have progressively changed, shifting from an infectious and AIDS-related disease majority to chronic and non-AIDS conditions predominance, such as hepatic, pulmonary, and cardiovascular illnesses ${ }^{6}$. In this context, the present work represents one of the main studies to investigate risk factors for death among HIV-infected patients in our region.

When analyzing demographic data, we noticed that the studied population included a majority of males, as well as young and middle-aged people $(<40$ years $=58 \%$ ). Older age has frequently been linked to elevated mortality among HIV patients, due to a higher incidence of comorbidities and lesser adherence to treatment. On the other hand, in a large epidemiolog-

FIGURE 2 - Comparison of associated infections between survivors and non-survivors.

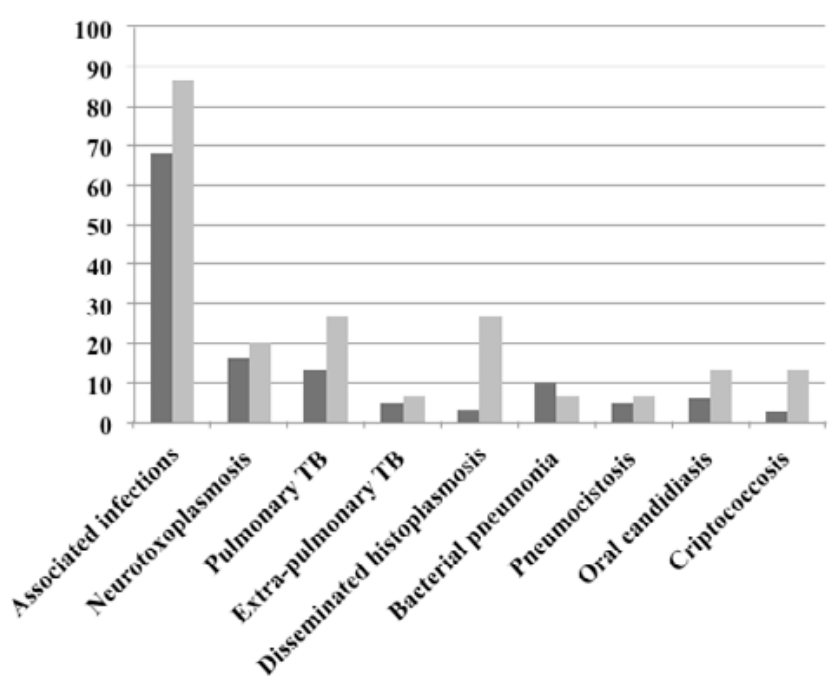


ical Chinese study, death was more common among those who were $20-49$ years old, similarly to the majority of our patients?

In the present study, the percentage of males was higher among non-survivors than in survivors. Higher mortality in males has been extensively reported, mostly due to late referencing of men to HIV care and poor adherence to treatment ${ }^{10}$. Studies have demonstrated that women tend to initiate HAART sooner, which can be linked to HIV screening in prenatal exams for all pregnant women, which is mandatory in Brazil since 1996. On the other hand, men tend to look for medical attention only when they manifest symptoms, leading to late diagnosis and treatment ${ }^{11}$. We also observed that non-survivors had a shorter hospitalization time, mostly because they frequently died a few days after admission due to an acute condition or a complication.

Interestingly, HAART use was not significantly different between groups in the present study. Many studies have associated antiretroviral therapy with reduction of mortality, and its introduction may be considered one of the most important advances in the history of HIV infection, since it was responsible for reducing several complications and poor outcomes, including death ${ }^{12}$. Considering the fact that HAART use in the studied population did not influence CD4 lymphocytes count and viral load in both groups, we hypothesize that the lack of mortality decrease secondary to HAART use derives from a combination of irregular administration and insufficient information from charts. When data were collected, only basic information of previous HAART use was available in the charts (yes or no), but it was not described if these medications were being adequately taken by the patients, or how long they have been taking them. Hence, we believe that some patients who were classified as using HAART were not taking it correctly, leading to no difference between groups regarding HAART use, CD4 lymphocytes count, and viral load.

According to several studies, the general incidence of AKI on HIV-infected individuals is about 2.8$5.9 \%$ per year in outpatients, $6-18 \%$ in hospitalized patients, and $47.4 \%$ in critically ill patients ${ }^{13-15}$. In the present study, non-survivors had a significantly higher incidence of AKI and oliguria, needed more renal replacement therapy, and presented higher levels of urea and creatinine. Among hospitalized patients, AKI is more common in HIV-infected individuals than in the general population, as expected.

In the pre-HAART era, pre-renal azotemia was the unquestionable main form of AKI in HIV-infected patients, caused by volume depletion, associated infection, and sepsis ${ }^{16}$. On the other hand, in the postHAART era AKI etiology changed and became multifactorial. Currently, volume depletion and sepsis are

TABLE 2 - COMPARISON OF LABORATORY DATA ON ADMISSION BETWEEN SURVIVORS AND NON-SURVIVORS.

\begin{tabular}{l|l|l|l} 
& Survivors $(\mathrm{N}=185)$ & Non-survivors $(\mathrm{N}=15)$ & $\mathrm{P}$ \\
\hline MVL $\left(10^{3}\right.$ copies $\left./ \mathrm{mm}^{3}\right)$ & $187.3(0-3707)$ & $162.4(0.3-639.2)$ & 0.953 \\
\hline CD4 Lymphocytes $\left(/ \mathrm{mm}^{3}\right)$ & $277(12-1456)$ & $167(38-363)$ & 0.445 \\
\hline Hemoglobin $(\mathrm{g} / \mathrm{dL})$ & $10.7 \pm 2.5$ & $9.5 \pm 2.6$ & 0.07 \\
\hline Hematocrit $(\%)$ & $32.5 \pm 7.2$ & $28.0 \pm 9.1$ & 0.023 \\
\hline Leukocytes $\left(10^{3} / \mathrm{mm}^{3}\right)$ & $6.88(0.59-46)$ & $12.42(0.99-64)$ & 0.323 \\
\hline Platelets $\left(10^{3} / \mathrm{mm}^{3}\right)$ & $218.9 \pm 107.7$ & $166.0 \pm 94.5$ & 0.076 \\
\hline Urea $(\mathrm{mg} / \mathrm{dL})$ & $36.1 \pm 29.1$ & $73.8 \pm 52.7$ & $<0.001$ \\
\hline Creatinine $(\mathrm{mg} / \mathrm{dL})$ & $1.05 \pm 1.07$ & $1.98 \pm 1.65$ & $<0.001$ \\
\hline Sodium $(\mathrm{mEq} / \mathrm{L})$ & $135.4 \pm 5.2$ & $133.0 \pm 9.4$ & 0.241 \\
\hline Potassium $(\mathrm{mEq} / \mathrm{L})$ & $3.9 \pm 0.7$ & $4.8 \pm 1.7$ & 0.099 \\
\hline AST $(\mathrm{U} / \mathrm{L})$ & $84.8(7-1428)$ & $130.8(20-2180)$ & 0.003 \\
\hline ALT $(\mathrm{U} / \mathrm{L})$ & $85.4(2-1316)$ & $115.6(8-118)$ & 0.045 \\
\hline LDH $(\mathrm{U} / \mathrm{L})$ & $608(204-3294)$ & $1208(280-4184)$ & 0.012 \\
\hline pH & $7.40(7.00-7.56)$ & $7,35(6.9-7.52)$ & 0.674 \\
\hline HCO3 $(\mathrm{mEq} / \mathrm{L})$ & $21.6 \pm 4.6$ & $18.0 \pm 4.7$ & 0.016 \\
\hline PCO2 $(\mathrm{mmHg})$ & $33.0 \pm 9.3$ & $27.8 \pm 7.7$ & 0.05 \\
\hline
\end{tabular}

MVL - mean viral load; AST - aspartate aminotransferase; ALT - alanine aminotransferase; LDH - lactate dehydrogenase; HCO3 - arterial bicarbonate; PCO2 arterial carbon dioxide partial pressure. Student's t-test and Mann-Whitney $U$ test were used. $P$ values $<0.05$ were considered statistically significant. 
TABLE 3 - RISK FACTORS FOR DEATH AMONG HIV INFECTED PATIENTS.

\begin{tabular}{l|l|l|l} 
Factor & OR & $95 \% \mathrm{Cl}$ & $\mathrm{P}$ \\
\hline $\mathrm{AKI}$ & 18.045 & $4.308-75.596$ & $<0.001$ \\
\hline $\mathrm{DH}$ & 12.696 & $1.618-99.646$ & 0.016 \\
\hline Disorientation & 5.523 & $1.130-26.998$ & 0.035 \\
\hline $\mathrm{LDH}>1000 \mathrm{U} / \mathrm{L}$ & 4.854 & $1.093-21.739$ & 0.038 \\
\hline Dyspnea & 4.064 & $1.028-16.073$ & 0.046 \\
\hline
\end{tabular}

AKI - acute kidney injury; LDH - lactate dehydrogenase; DH - Disseminated Histoplasmosis. A logistic Regression model was used.

still important causes of AKI, but other factors like liver disease and drug toxicity have also become major etiologies ${ }^{17}$. Many conditions have been proposed as risk factors for AKI in this group, including low CD4+ count, elevated viral loads, previous renal disease, drug toxicity, underweight, older age, diabetes mellitus, cardiovascular disease, liver dysfunction, and hepatitis $\mathrm{C}$ coinfection ${ }^{12,14}$. Similarly to what we have observed in the present research, several other studies have demonstrated the role of AKI as a predictor of both short and long-term mortality in HIV-infected individuals, as well as its association with other poor outcomes, like heart failure and end-stage renal disease (ESRD) ${ }^{14,18}$. In the present study, severe forms of AKI were more prevalent in non-survivors. As previously described, they were considered an important risk factor for in-hospital HIV mortality ${ }^{\mathbf{1 9}, 20}$.

Additionally, we noticed that patients in the non-survivors group had significantly lower levels of serum bicarbonate and arterial CO2 partial pressure, which represents a higher incidence of metabolic acidosis and hyperventilation. Acidosis has been recognized as a consequence of AKI in HIV patients and has been described as a risk factor for death in this population $^{21}$. We believe that AKI was the primary cause of metabolic acidosis, but other factors may have contributed, such as drug toxicity by the nucleoside/nucleotide reverse transcriptase inhibitors (NRTI/NtRTIs) ${ }^{22}$. Several studies have demonstrated that drugs like stavudine, didanosine, zidovudine, lamivudine, abacavir, and tenofovir may cause acidosis through different mechanisms, such as mitochondrial dysfunction, Fanconi syndrome (proximal acidosis), and distal renal tubular acidosis ${ }^{23,24}$. In a previous study from our group with pediatric HIV patients, we observed that metabolic acidosis also happened as a consequence of HAART use ${ }^{25}$.

Regarding liver involvement, non-survivors presented significantly higher levels of AST and ALT on admission. An extensive study by Weber et al. ${ }^{26}$ showed that liver-related diseases caused $14.5 \%$ of all deaths and were the first cause of non-AIDS-related deaths. Many different factors may be linked to liver dysfunction in HIV patients, including hepatitis B (HBV) and C (HCV) coinfection, steatosis and non-alcoholic steatohepatitis (NASH), insulin resistance, drug toxicity, and direct effect of HIV ${ }^{27}$. It is difficult to define which factors are responsible for liver injury in our patients, but interestingly none of them tested positive for HBV or HCV. These infections share transmission routes with HIV and are observed in 5-25\% of all HIV-infected patients worldwide but are usually overshadowed by opportunistic infections and hepatotoxic drugs as causes of liver injury ${ }^{28}$.

Pulmonary infections are widespread in immunocompromised hosts, even in the HAART era and nearly $70 \%$ of HIV patients will experience respiratory complications at some point in their disease $^{29}$. Pulmonary complications are the leading cause of hospitalization ${ }^{30}$ and the leading causes of respiratory involvement in developed countries are bacterial pneumonia, bronchitis , and Pneumocystis jiroveci pneumonia. Tuberculosis is still a frequent complication of HIV-infection in developing countries, while it is becoming rare in the developed world ${ }^{31}$. In the present study, dyspnea on admission was a risk factor for death in the multivariate analysis, which reflects pulmonary involvement. Other studies have shown that pulmonary infections are risk factors for death even in the HAART era, and HIV-patients are at higher risk of these conditions. However, it was not assessed whether the clinical symptom of dyspnea on admission was associated with higher mortality ${ }^{32}$.

Additionally, disorientation was another important finding on admission. HIV-infection may cause disorientation for a myriad of reasons, including psychiatric comorbidities, immune dysfunction, HIV infection of the central nervous system (CNS), or progression of a systemic disease ${ }^{33}$. Although HAART treatment may prevent mental status alterations by precluding some of the above-mentioned complications, it can be the cause of the disorientation itself ${ }^{34}$. In the present study, disorientation was another risk factor for death, increasing mortality more than five-fold, in accordance with previous studies ${ }^{35}$. However, altered mental status has been demonstrated to increase mortality not only when there is ongoing HIV-associated CNS infection, but also in general wards $^{36,37}$. Such findings suggest that the increase in 
the risk of death derives primarily from the progression of the systemic disease, rather than from the infection of the CNS.

Among the myriad of HIV-associated infections, histoplasmosis is an important and dangerous global systemic mycosis caused by H. capsulatum. It is endemic in the Americas and has a notably high incidence in the state of Ceará, where this study was conducted $^{38,39}$. It is considered an opportunistic infection which usually affects HIV patients with low CD4 levels, occurring in up to 5\% of HIV infected patients in endemic areas ${ }^{40}$. Recent studies have stated that Histoplasma infection is more widespread than previously thought and its morbidity and mortality have been hugely underestimated due to severe underdiagnosing and underreporting ${ }^{41}$. The clinical presentation of this harmful disease may vary from asymptomatic infection with fever, chills, headache and malaise, to a life-threatening disseminated condition with septic shock, renal dysfunction, hepatic failure, acute respiratory distress syndrome and coagulopathy ${ }^{39}$. In addition, disseminated histoplasmosis [DH] has been described as an AIDS-defining condition, which usually occurs early in the course of HIV untreated infection and could even be the first manifestation of AIDS in some cases ${ }^{42}$.

Unfortunately, poor outcomes are still very common in HIV patients with DH. Mortality rates among these patients can reach almost 50\%, more prominently when severe manifestations like sepsis, renal failure, and pulmonary insufficiency are present $^{43}$. In the studied population, DH was more common among non-survivors than survivors and it was a significant predictor of death in multivariate analysis. Histoplasmosis remains an important cause of death in HIV patients, and it has been described as the third most fatal mycosis among this population in Brazil ${ }^{44}$. Both early and long-term histoplasmosis mortality rates have been decreasing since the introduction of HAART, and antiretroviral use has been described as the most critical variable that influenced mortality reduction ${ }^{45}$. Several factors have been associated with mortality in patients with HIV-DH coinfection. Some authors demonstrated that high levels of creatinine and low levels of serum albumin were related to poor outcomes while others found that dyspnea, thrombocytopenia, and increased lactate dehydrogenase (LDH) levels were associated with mortality ${ }^{40,46}$. In a previous study from our group, other factors like diarrhea, neurologic manifestations, low hemoglobin levels, increases serum urea, liver involvement, respiratory insufficiency, and AKI were also linked to death in this population ${ }^{47}$.

On the other hand, LDH levels were significantly lower in survivors group than in nonsurvivors, and LDH $>1000 U / L$ was a risk factor for death among our patients. In the present context, increased LDH levels are strongly related to histoplasmosis and may be used to differentiate this infection from Pneumocystis jiroveci pneumonia $(\mathrm{PJP})^{48}$. In a previous study with HIV-infected patients from our group, we found higher levels of LDH in histoplasmosis than in other opportunistic infections ${ }^{39}$. Other authors have found that levels of LDH activity $>2$ times the upper limit of the normal range was a predictor of death ${ }^{46}$.

In recent years, it has been stated that the significant LDH increase in histoplasmosis was associated with the development of hemophagocytic syndrome. This syndrome, also known as hemophagocytic lymphohistiocytosis (HLH), results from unregulated macrophage activation with overproduction of inflammatory cytokines, leading to hemophagocyto$\operatorname{sis}^{49}$. It may be primary or secondary, triggered by hematologic malignancies, autoimmune diseases, or several infections, such as DH and HIV itself ${ }^{50}$. There is still scarce information about histoplasmosis-associated HLH, but it is recognized as a high-mortality condition $^{50}$. Considering the intimate relationship between LDH and DH in the HIV setting, we believe that the role of elevated LDH levels as a risk factor for death derives from its connection to higher DH incidence and consequently more HLH. Since DH has been recognized as an underestimated and underdiagnosed global burden, further studies are necessary to investigate the connection between LDH, HLH, and mortality in DH patients.

In conclusion, neurologic impairment, pulmonary and respiratory involvement and AKI development were considered risk factors for death in HIV-infected patients. Disseminated histoplasmosis and elevated levels of lactate dehydrogenase (LDH) were also predictors of death in this population.

\section{STUDY LIMITATIONS}

This study has many limitations. The most important of them derives from its retrospective nature. Patients' data were retrospectively collect- 
ed from medical charts, and we unfortunately did not have access to some of the patients' information. Also, retrospective studies are at higher risk of presenting biases. The significant difference in the number of patients in each group may be considered a limitation, since it makes statistical analysis more difficult and significantly influences results. However, we have chosen to compare these groups and investigate risk factors for death due to the importance of this subject, despite statistical difficulties.

\section{ACKNOWLEDGMENTS}

We are very grateful to the team of attendant physicians, residents, medical students, and nurses from São José Infectious Diseases Hospital for the assistance provided to the patients and for the technical support provided to the development of this research. This research was supported by the Brazilian National Council for Scientific and Technological Development - CNPq.

\section{Conflicts of interest}

We declare not having any conflicts of interest.

\section{RESUMO}

INTRODUçÃo: A mortalidade relacionada ao HIV ainda é alta, especialmente nos países em desenvolvimento. O objetivo deste estudo é investigar os fatores associados ao óbito em pacientes com HIV.

MÉTODOS: Trata-se de um estudo transversal com todos os pacientes com HIV admitidos consecutivamente em um hospital terciário de doenças infecciosas em Fortaleza, Nordeste do Brasil, entre janeiro de 2013 e dezembro de 2014. Os pacientes foram divididos em dois grupos: sobreviventes e não sobreviventes. Dados demográficos, clínicos e laboratoriais foram comparados e análise de regressão logística foi feita para investigação dos fatores de risco para óbito.

RESULTADOS: Um total de 200 pacientes, com média de idade de 39 anos, foi incluído no estudo, sendo 69,5\% do sexo masculino. Óbito ocorreu em 15 pacientes (7,5\%). Os não sobreviventes apresentaram maior percentual de homens (93,3 vs. 67,3\%, $p=0,037)$ e um menor tempo de internação ( $8 \pm 6$ vs. $18 \pm 15$ dias, $p=0,005)$. Na análise multivariada, desorientação $(p=0,035,0 R=5,523)$, dispneia $(p$ $=0,046, O R=4,064), L R A(p<0,001, O R=18,045)$, histoplasmose disseminada $(p=0,016, O R=12,696)$ e desidrogenase lática $(L D H)$ $>1.000 \mathrm{U} / \mathrm{L}(p=0,038, O R=4,854)$ foram fatores de risco para óbito.

CONCLUSÕES: LRA e histoplasmose disseminada foram os principais fatores de risco para óbito na população estudada. Distúrbios neurológicos e respiratórios, bem como níveis elevados de $\mathrm{LDH}$, também estiveram associados com o aumento da mortalidade em pacientes com HIV.

PALAVRAS-CHAVE: HIV. Mortalidade. Fatores de risco. Histoplasmose. Lesão renal aguda.

\section{REFERENCES}

1. UNAIDS. AIDS by the numbers, 2016. [cited 2017 February 15] Available from: http://www.unaids.org/sites/default/files/media_asset/AIDS-bythe-numbers-2016_en.pdf

2. UNAIDS Global AIDS update, 2016. [cited 2017 February 15] Available from: http://www.unaids.org/sites/default/files/media_asset/global-AIDSupdate-2016_en.pdf.

3. Palella F| |r, Delaney KM, Moorman AC, Loveless MO, Fuhrer |, Satten GA et al. Declining morbidity and mortality among patients with advanced human immunodeficiency virus infection. HIV Outpatient Study Investigators. N Engl J Med. 1998;338(13):853-60.

4. Friis-Møller N, Sabin CA Weber R, d'Arminio Monforte A, El-Sadr WM Reiss P, et al; Data Collection on Adverse Events of Anti-HIV Drugs (DAD) Study Group. Combination antiretroviral therapy and the risk of myocardial infarction. N Engl J Med. 2003;349(21):1993-2003.

5. Ryom L, Mocroft A, Kirk O, Worm SW, Kamara DA, Reiss P, et al. Association between antiretroviral exposure and renal impairment among HIV-positive persons with normal baseline renal function: the D:A:D study. I Infect Dis. 2013;207(9):1359-69.

6. Palella FJ Jr, Baker RK, Moorman AC, Chmiel JS, Wood KC, Brooks JT, et al. Mortality in the highly active antiretroviral therapy era: changing causes of death and disease in the HIV outpatient study. J Acquir Immune Defic Syndr. 2006;43(1):27-34.

7. Gonzalez MA, Martin L, Munoz S, Jacobson JO. Patterns, trends and sex differences in HIV/AIDS reported mortality in Latin American countries: 1996-2007. BMC Public Health. 2011;11:605.
8. Kidney Disease Outcomes Quality Initiative KDIGO clinical practice guidelines for acute kidney injury. Kidney Int Suppl. 2012;2(supl 1):1-138.

9. Seyoum D, Degryse JM, Kifle YG, Taye A, Tadesse M, Birlie B, et al. Risk factors for mortality among adult HIV/AIDS patients following antiretroviral therapy in Southwestern Ethiopia: an assessment through survival models. Int J Environ Res Public Health. 2017;74(3). pii:E296.

10. Mageda K, Leyna GG, Mmbaga E). High initial HIV/AIDS-related mortality and-its predictors among patients on antiretroviral therapy in the Kagera region of Tanzania: a five-year retrospective cohort study. AIDS Res Treat. 2012;2012:843598.

11. Patricio FR, Rutherford GW, Barreto JH, Rodamilans C, Badaró R. Effectiveness of the prevention of mother-to-child HIV transmission in Bahia, Brazil. Braz | Infect Dis. 2015;19(5):538-42.

12. Zolopa A, Andersen I, Powderly W, Sanchez A, Sanne I, Suckow C, et al. Early antiretroviral therapy reduces AIDS progression/death in individuals with acute opportunistic infections: a multicenter randomized strategy trial. PLoS One. 2009;4(5):e5575.

13. Franceschini N, Napravnik S, Eron || |rr, Szczech LA, Finn WF. Incidence and etiology of acute renal failure among ambulatory HIV-infected patients. Kidney Int. 2005;67(4):1526-31.

14. Wyatt $C M$, Arons RR, Klotman PE, Klotman ME. Acute renal failure in hospitalized patients with HIV: risk factors and impact on in-hospital mortality. AIDS. 2006;20(4):561-5.

15. Lopes JA, Fernandes J, Jorge S, Neves J, Antunes F, Prata MM. An assess- 
ment of the RIFLE criteria for acute renal failure in critically ill HIV-infected patients. Crit Care. 2007;11(1):401.

16. Cohen SD, Chawla LS, Kimmel PL. Acute kidney injury in patients with human immunodeficiency virus infection. Curr Opin Crit Care. 2008;14(6):647-53.

17. Campos P, Ortiz A, Soto K. HIV and kidney diseases: 35 years of history and consequences. Clin Kidney J. 2016;9(6):772-781.

18. Choi Al, Li YM, Parikh C, Volberding PA, Shlipak MG. Long-term clinical consequences of acute kidney injury in the HIV-infected. Kidney Int. 2010;78(5):478-85

19. Prakash J, Gupta T, Prakash S, Rathore SS, Usha, Sunder S. Acute kidney injury in patients with human immunodeficiency virus infection. Indian I Nephrol. 2015;25(2):86-90.

20. Nadkarni GN, Patel AA, Yacoub R, Benjo AM, Konstantinidis I, Annapureddy $\mathrm{N}$, et al. The burden of dialysis-requiring acute kidney injury among hospitalized adults with HIV infection: a nationwide inpatient sample analysis. AIDS. 2015;29(9):1061-6.

21. Vachiat Al, Musenge E, Wadee S, Naicker S. Renal failure in HIV-positive patients: a South African experience. Clin Kidney J. 2013;6(6):584-9.

22. Margolis AM, Heverling $H$, Pham PA, Stolbach A. A review of the toxicity of HIV medications. | Med Toxicol. 2014;10(1):26-39.

23. Iwata K, Nagata M, Watanabe S, Nishi S. Distal renal tubular acidosis without renal impairment after use of tenofovir: a case report. BMC Pharmacol Toxicol. 2016;17(1):52.

24. Luni FK, Khan AR, Prashar R, Vetteth S, Duggan JM. Fanconi syndrome and antiretrovirals: it is never too late. Am J Ther. 2016;23(2):e558-60.

25. Soares DS, Cavalcante MG, Ribeiro SM, Leitão RC, Vieira AP, Pires Neto $\mathrm{RD}$, et al. Acute kidney injury in HIV-infected children: comparison of patients according to the use of highly active antiretroviral therapy. I Pediatr (Rio J). 2016;92(6):631-7.

26. Weber R, Sabin CA, Friis-Møller N, Reiss P, El-Sadr WM, Kirk O, et al. Liver-related deaths in persons infected with the human immunodeficiency virus: the D:A:D study. Arch Intern Med. 2006;166(15):1632-41.

27. Rockstroh JK, Mohr R, Behrens G, Spengler U. Liver fibrosis in HIV: which role does HIV itself, long-term drug toxicities and metabolic changes play? Curr Opin HIV AIDS. 2014;9(4):365-70.

28. Wnuk AM. Liver damage in HIV-infected patients. Med Sci Monit. 2001;7(4):729-36.

29. Benito N, Moreno A, Miro JM, Torres A. Pulmonary infections in HIV-infected patients: an update in the 21 ${ }^{\text {st }}$ century. Eur Respir ). 2012;39(3):73045

30. Berry SA, Fleishman IA, Moore RD, Gebo KA; HIV Research Network. Trends in reasons for hospitalization in a multisite United States cohort of persons living with HIV, 2001-2008. I Acquir Immune Defic Syndr. 2012;59(4):368-75.

31. Fitzpatrick M, Brooks IT, Kaplan IE. Epidemiology of HIV-associated lung disease in the United States. Semin Respir Crit Care Med. 2016;37(2):181-98

32. Gingo MR, Balasubramani GK, Kingsley L, Rinaldo CR Jr, Alden CB, Detels $R$, et al. The impact of HAART on the respiratory complications of HIV infection: longitudinal trends in the MACS and WIHS cohorts. PLoS One. 2013;8(3):e58812.

33. Ho EL, Jay CA. Altered mental status in HIV-infected patients. Emerg Med Clin North Am. 2010;28(2):311-23.
34. Treisman G], Kaplin Al. Neurologic and psychiatric complications of antiretroviral agents. AIDS. 2002;16(9):1201-15.

35. Jarvis IN, Bicanic T, Loyse A, Namarika D, Jackson A, Nussbaum IC, et al. Determinants of mortality in a combined cohort of 501 patients with HIV-associated Cryptococcal meningitis: implications for improving outcomes. Clin Infect Dis. 2014;58(5):736-45.

36. Harrington B, Kyriakos Vorkas C, Kanyama C, Ngoma I, Hoffman I, Hosseinipour MC. Altered mental status is an indicator of mortality and associated with both infectious and non-communicable disease in Lilongwe, Malawi. Trop Doct. 2015;45(3):164-7.

37. Zadravecz F|, Tien L, Robertson-Dick B|, Yuen TC, Twu NM, Churpek MM, et al. Comparison of mental-status scales for predicting mortality on the general wards. J Hosp Med. 2015;10(10):658-63.

38. Brilhante RS, Fechine MA, Mesquita IR, Cordeiro RA, Rocha MF, Monteiro AJ, et al. Histoplasmosis in HIV-positive patients in Ceará, Brazil: clinical-laboratory aspects and in vitro antifungal susceptibility of Histoplasma capsulatum isolates. Trans R Soc Trop Med Hyg. 2012;106(8):484-8.

39. Daher EF, Silva GB Jr, Barros FA, Takeda CF, Mota RM, Ferreira MT, et al. Clinical and laboratory features of disseminated histoplasmosis in HIV patients from Brazil. Trop Med Int Health. 2007;12(9):1108-15.

40. Wheat LI, Chetchotisakd P, Williams B, Connolly P, Shutt K, Hajjeh R. Factors associated with severe manifestations of histoplasmosis in AIDS. Clin Infect Dis. 2000;30(6):877-81.

41. Antinori S. Histoplasma capsulatum: more widespread than previously thought. Am J Trop Med Hyg. 2014;90(6):982-3.

42. Sarosi GA, Johnson PC. Disseminated histoplasmosis in patients infected with human immunodeficiency virus. Clin Infect Dis. 1992;14(Suppl 1):S60-7.

43. Baddley |W, Sankara IR, Rodriquez |M, Pappas PG, Many W| |r. Histoplasmosis in HIV-infected patients in a southern regional medical center: poor prognosis in the era of highly active antiretroviral therapy. Diagn Microbio Infect Dis. 2008;62(2):151-6.

44. Prado M, Silva MB, Laurenti $R$, Travassos LR, Taborda CP. Mortality due to systemic mycoses as a primary cause of death or in association with AIDS in Brazil: a review from 1996 to 2006. Mem Inst Oswaldo Cruz. 2009;104(3):513-21.

45. Damasceno LS, Ramos NA Ir, Alencar CH, Gonçalves MV, Mesquita IR, Soares AT, et al. Disseminated histoplasmosis in HIV-infected patients: determinants of relapse and mortality in a north-eastern area of Brazil. Mycoses. 2014;57(7):406-13.

46. Couppié P, Sobesky M, Aznar C, Bichat S, Clyti E, Bissuel F, et al. Histoplasmosis and acquired immunodeficiency syndrome: a study of prognostic factors. Clin Infect Dis. 2004;38(1):134-8

47. De Francesco Daher E, Sousa Barros FA, Silva Júnior GB, Takeda CF, Mota RM, Ferreira MT, et al. Risk factors for death in acquired immunodeficiency syndrome-associated disseminated histoplasmosis. Am J Trop Med Hyg. 2006;74(4):600-3.

48. Butt AA, Michaels S, Greer D, Clark R, Kissinger P, Martin DH. Serum $\mathrm{LDH}$ level as a clue to the diagnosis of histoplasmosis. AIDS Read. 2002;12(7):317-21.

49. Castelli AA, Rosenthal DG, Bender Ignacio R, Chu HY. Hemophagocytic lymphohistiocytosis secondary to human immunodeficiency virus-associated histoplasmosis. Open Forum Infect Dis. 2015;2(4):ofv140

50. Townsend JL, Shanbhag S, Hancock J, Bowman K, Nijhawan AE. Histoplasmosis-induced hemophagocytic syndrome: a case series and review of the literature. Open Forum Infect Dis. 2015;2(2):ofv055. 